\title{
The Characteristics and Level of Evidence of Clinical Studies Published in 5 Leading Orthodontic Journals
}

DOI:

10.1016/j.jebdp.2019.03.001

10.1016/j.jebdp.2019.03.001

\section{Document Version}

Accepted author manuscript

Link to publication record in Manchester Research Explorer

\section{Citation for published version (APA):}

Chen, Y., Hua, F., Mei, Y., Thiruvenkatachari, B., Riley, P., \& He, H. (2019). The Characteristics and Level of Evidence of Clinical Studies Published in 5 Leading Orthodontic Journals. Journal of Evidence-Based Dental Practice, 19(3), 273-282. https://doi.org/10.1016/j.jebdp.2019.03.001, https://doi.org/10.1016/j.jebdp.2019.03.001

\section{Published in:}

Journal of Evidence-Based Dental Practice

\section{Citing this paper}

Please note that where the full-text provided on Manchester Research Explorer is the Author Accepted Manuscript or Proof version this may differ from the final Published version. If citing, it is advised that you check and use the publisher's definitive version.

\section{General rights}

Copyright and moral rights for the publications made accessible in the Research Explorer are retained by the authors and/or other copyright owners and it is a condition of accessing publications that users recognise and abide by the legal requirements associated with these rights.

\section{Takedown policy}

If you believe that this document breaches copyright please refer to the University of Manchester's Takedown Procedures [http://man.ac.uk/04Y6Bo] or contact uml.scholarlycommunications@manchester.ac.uk providing relevant details, so we can investigate your claim.

\section{OPEN ACCESS}




\section{The Characteristics and Level of Evidence of Clinical Studies Published in Five Leading Orthodontic Journals}

Yiwen Chen ${ }^{1+}$, Fang Hua 1,2,3+, Yan Mei 1, Badri Thiruvenkatachari ${ }^{3}$, Philip Riley ${ }^{3}$,

Hong $\mathrm{He}^{1 *}$

1. Department of Orthodontics, Hubei-MOST KLOS \& KLOBM, School \& Hospital of Stomatology, Wuhan University, Wuhan, China.

2. Centre for Evidence-Based Stomatology, Hubei-MOST KLOS \& KLOBM, School \& Hospital of Stomatology, Wuhan University, Wuhan, China

3. Division of Dentistry, School of Medical Sciences, Faculty of Biology, Medicine and Health, University of Manchester, Manchester Academic Health Science Centre, Manchester, UK.

+ These authors are joint first authors and contributed equally to this work.

* Corresponding Author:

Prof. Hong He, Department of Orthodontics, Hubei-MOST KLOS \& KLOBM, School \& Hospital of Stomatology, Wuhan University, Luoyu Road 237, Wuhan 430079, China.

E-mail: drhehong@whu.edu.cn

\section{How to Cite:}

Chen Y, Hua F, Mei Y, Thiruvenkatachari B, Riley P, He H. The Characteristics and Level of Evidence of Clinical Studies Published in Five Leading Orthodontic Journals. Journal of Evidence-based Dental Practice, 2019. doi: 10.1016/j.jebdp.2019.03.001. doi: $10.1016 /$ j.jebdp.2019.03.001.

PMID: 28669693

Please note that this is a post-print version (after peer-review) for the purpose of selfarchiving. Please download the final published version from the publisher's website: https://www.sciencedirect.com/science/article/pii/S153233821830366X?via\%3Dihub 


\begin{abstract}
Objectives: To assess the characteristics and level of evidence (LOE) of clinical studies recently published in leading orthodontic journals, and explore the association between LOE and potentially related factors.
\end{abstract}

Methods: The official online archives of five leading orthodontic journals were handsearched to identify clinical research articles published during 2015 to 2017 . The LOE of all included studies was assessed using a modified LOE classification system developed based on the Oxford LOE and GRADE (Grading of Recommendations Assessment, Development and Evaluation). Univariable and multivariable logistic regression analyses were performed to identify the association between the LOE of each article (high LOE vs. low LOE) and 7 factors.

Results: A total of 637 studies were included and assessed. Of these, 8 (1.3\%) were level-1 studies, 160 (25.1\%) were level-2, 326 (51.2\%) were level-3, and 143 (22.4\%) were level-4. According to multivariable logistic regression analyses, journal of publication $(\mathrm{P}<0.001)$, funding status $(\mathrm{P}=0.003)$, and the geographic origin of the first author $(\mathrm{P}=0.006)$ were significantly associated with LOE.

Conclusions: The number of high LOE studies in leading orthodontic journals was limited. There is still need for further improvement in the overall LOE of clinical studies in orthodontics.

Key words: orthodontics, clinical studies, evidence-based orthodontics, level of evidence 


\section{Introduction}

Evidenced-Based Medicine (EBM) has been regarded as a major landmark during the progression of medicine. ${ }^{1}$ As a combination of research evidence, clinical expertise and patient preferences, ${ }^{2,3} \mathrm{EBM}$ aims to enable the safe, reliable and cost-efficient delivery of healthcare to patients. ${ }^{4,5}$ However, the practice of EBM has been associated with challenges in all domains of healthcare because of the explosive growth of articles published. ${ }^{6}$ Lack of time and heavy workload are also widely accepted barriers to evidence-based practice (EBP) for clinicians. ${ }^{7}$ Due to the above-mentioned factors and a lack of awareness and understanding of EBP, ${ }^{8}$ many orthodontists still prefer to rely on the opinion of experts and colleagues when faced with clinical uncertainties. ${ }^{9}$

The advent of Levels of Evidence (LOE) allows readers to complete a quick overview of a study's methodological quality. ${ }^{5}$ In general, studies with higher LOE have better reproducibility and more reliable outcomes. ${ }^{10,11}$ Oxford LOE, developed by Oxford Centre for Evidence-Based Medicine, is one of the most widely used LOE classification tools. ${ }^{5,12}$ Different from other LOE assessment tools, the latest version Oxford LOE (2011) takes into account not only the design of studies, but also their results. ${ }^{5,13}$ Similar to the methods used in GRADE, for an observational study, when the magnitude of effect is regarded as dramatic, its LOE should be rated up. ${ }^{13,14}$ However, the Oxford 2011 LOE did not provide an explicit standard for the judgement of 'dramatic effect', making it difficult for readers / clinicians to determine whether or not to rate up an observational study during making clinical decision.

The year of 2017 marks the 20th year after the concept of evidence-based orthodontics (EBO) was proposed by Sheldon Peck in Angle Orthodontist. ${ }^{15}$ However, to our knowledge, the current LOE status of the orthodontic literature has not been assessed. In addition, despite the aforementioned advantages of Oxford 2011 LOE, most previous LOE related studies either used an obsolete version ${ }^{16-18}$ or did not consider the effect sizes when assessing observational studies. ${ }^{11,12,19}$ Therefore, the primary objective of this study was to assess the characteristics and LOE of recently published clinical research articles in leading orthodontic journals, using the Oxford 2011 LOE accompanied with the rating up standards of GRADE. A secondary objective was to investigate and explore the association between LOE and potentially related factors, such as funding status, geographic origin and type of institution. 


\section{Methods and Materials}

Journal selection

We used the Thomson Reuters 2016 Journal Citation Report (JCR) ${ }^{20}$ to select the top5 SCIE-indexed orthodontic journals that have the highest impact factors (IF), i.e. European Journal of Orthodontics (EJO, IF=1.622), American Journal of Orthodontics and Dentofacial Orthopedics (AJO-DO, 1.472), Angle Orthodontist (AO, 1.366), Korean Journal of Orthodontics (KJO, 1.182) and Orthodontics \& Craniofacial Research (OCR, 1.115).

\section{Article selection}

The official online archives of all five selected journals were hand-searched to identify clinical research articles published in these journals from January 2015 to December 2017. Pre-determined inclusion criteria were original studies with patients receiving orthodontic care in the clinical setting. When the eligibility of a study cannot be determined based on its title and abstract, the full-text was retrieved and screened. Two authors (Y.C and Y.M) carried out all the hand search and screening procedures independently and in duplicate, with any uncertainty resolved by consulting two experts (F.H and H.H) until consensus was reached.

\section{Data extraction}

For each included article, we extracted the following information: title of article, title of journal, IF, publication year, study design, funding status, number of institutions (single vs. multiple), name of institutions, and geographical origin (first author). If the first author had more than one affiliation, only the first one was extracted. In addition, we classified all institutions into 4 types: 1) university, 2) public health service, 3) private practice and 4) others. ${ }^{21}$ Funding status was categorized into: 1) funded by industry, 2) funded by other sources and 3) unfunded/unreported.

Initially, one author (Y.C) carried out the data extraction process. Thereafter, a 10\% random sample of the extracted data was examined by another author (Y.M). This process could reveal items for which a discrepancy exists between two reviewers on at least one occasion. One author (Y.C) then verified the data for these items from all articles. $^{22}$ 


\section{Assessment of $L O E$}

All articles were classified into four levels of evidence (Table 1) using a modified LOE classification system developed based on Oxford 2011 LOE, Oxford 2009 LOE, and the GRADE (Grading of Recommendations Assessment, Development and Evaluation) guidelines. ${ }^{13,14,23-26}$ For ease of description, we defined level-1 \& -2 as high level, level$3 \&-4$ as low level.

An internal pilot study was performed to calibrate examiners in the assessment of LOE and to indicate necessary refinement of the assessment protocol. During this process, two authors (Y.C and F.H.) carried out independent assessments in rounds of 15 randomly selected articles, until significant agreement was reached (weighted kappa statistics, $\mathrm{k}>0.61) .{ }^{27}$ Then, one author (Y.C) assessed the LOE of all remaining articles. All uncertainties were resolved by discussing with two experts (F.H and H.H).

\section{Statistical analyses}

We used descriptive statistics to summarize characteristics of included articles. Univariable and multivariable logistic regression analyses were performed to investigate the association between LOE (dependent variable; high LOE vs. low LOE) and 7 potential related factors (independent variables). Previous literature has suggested significant associations between LOE and the following factors: journal of publication, funding status, geographical origin (first author), and number of authors. ${ }^{16,28,29} \mathrm{We}$ decided a priori to study three more factors, i.e. type of institution, number of affiliations, and the international ranking of the first affiliation (according to 2018 QS ranking of the top-50 dental schools). ${ }^{30}$ All explanatory variables with $\mathrm{P}<0.1$ in univariable analyses were entered into multivariable modelling. For all statistical analyses, a two-sided $\mathrm{P}<0.05$ was set as the criterion for statistical significance.

\section{Sensitivity analysis}

According to GRADE, the quality of evidence should be rated up if the risk ratio (RR) of a study was greater than 2 (or less than 0.5 ) or greater than 5 (or less than 0.2 ), which was recognized as strong $(+1$ grade) or very strong ( +2 grades) association, respectively. ${ }^{14,29}$ In the main analysis, we decided to define $\mathrm{RR}>5($ or $<0.2)$ as dramatic effect. To evaluate the influence of this definition, a post hoc sensitivity analysis was 
carried out by repeating our analyses with dramatic effect being defined as $R R>2$ $($ or $<0.5)$.

\section{Results}

\section{Characteristics of the included articles}

A total of 2100 articles were identified during the hand search, of which 637 remained after applying the eligibility criteria (Figure 1). Data regarding the characteristics of these articles were listed in Table 2.

The majority of authors of included studies worked in universities (86.7\%). Most articles were collaborative work by multiple affiliations $(67.5 \%)$, some of which were international collaboration (27.9\%), while only one-third obtained financial support $(32.2 \%)$.

In terms of geographic origin, most of the included articles were published in $A J O$ $D O(40.3 \%)$ or $A O(30.9 \%)$, with a geographical origin in Europe $(41.1 \%)$ or Asia (30.1\%). Journals based in Europe (EJO and OCR) and Asia $(K J O)$ published more studies from the corresponding continent, with the percentage being $71.6 \%, 55.6 \%$ and $69.2 \%$, respectively. Whereas journals originated from America (AJO-DO and $A O$ ) presented a relatively even distribution of studied from different continents. Compared with three non-European journals,

Cohort study was most widely used study design among the included studies (50.1\%), followed by RCT (18.1\%) and case series/case report (17.9\%). The EJO and $O C R$ had a relatively higher proportion of SRs and RCTs, while the AJO-DO and $A O$ published more case-series and case reports.

\section{Results of LOE assessment}

During the internal pilot study, almost perfect agreement between 2 reviewers was reached in the first round $(\mathrm{k}=0.864,95 \%$ confidence interval $(\mathrm{CI}): 0.72$ to 1.00$)$. Of 637 studies, 3 studies met the rating up criteria. Finally, there were 8 level-1(1.26\%), 160 level-2 (25.12\%), 326 level-3 (51.18\%), and 143 level-4 (22.45\%) studies. EJO had the largest proportion of high LOE studies (48.4\%), followed by $A O(28.4 \%), A J O-D O$ (20.7\%), OCR (19.5\%) and KJO (11.5\%) (Figure 2). 
Results of sensitivity analysis. When we changed the definition of dramatic effect to $R R>2($ or $<0.5)$, the studies that met our rating up criteria remained the same $(n=3)$. The results of the above-mentioned main analyses were therefore robust.

\section{Factors associated with $L O E$}

Table 3 shows the results of logistic regression analyses. Univariable analyses showed that journal $(\mathrm{P}<0.001)$, geographical origin $(\mathrm{P}<0.001)$ and funding status $(\mathrm{P}=0.005)$ were significantly associated with LOE. No significant association was found between LOE and international collaboration ( $\mathrm{P}=0.681$ ), QS top-50 dental school $(\mathrm{P}=0.180)$, multiple affiliations $(\mathrm{P}=0.206)$, and type of institution $(\mathrm{P}=0.703)$.

In multivariable analysis, journal $(\mathrm{P}<0.001)$, funding status $(\mathrm{P}=0.003)$ and geographic origin $(\mathrm{P}=0.006)$ remained significantly associated with LOE. The odds of having high LOE were significantly higher in studies published in EJO than those published in other journals. Compared with studies funded by industry, the odds of having high LOE were $77.7 \%$ and $64.8 \%$ lower in studies that were unfunded/unreported and those funded by other sources, respectively. Compared with studies from Europe, the odds of having high LOE were significantly lower in studies from Asia and North America, and significantly higher in those from Africa.

\section{Discussion}

This study, based on a cross-sectional analysis of clinical research in 5 leading orthodontic journals during 3-year period, provides insight into the current pattern of LOE and identifies potential predictors.

The RCT, due to its ability to minimize bias, is regarded the optimal primary study design to determine the effectiveness of an intervention and therefore a level- 2 study. ${ }^{31}$ Our results indicate that $18.1 \%$ of the included studies were RCTs, and the proportion of RCTs in clinical studies has dramatically increased $(10.8 \%$ to $18.05 \%)$ when compared to data of a former analysis of orthodontic literature (1998-2008) ${ }^{32}$. Such a trend has been reported in other areas. ${ }^{33-35}$ The remarkable improvement in evidence among orthodontic research during the past two decades is probably associated with researchers' increasing recognition of EBO ${ }^{36,37}$ Another possible reason is researchers' preference to conduct and publish high quality studies to enhance their profile in a competitive academic environment. ${ }^{38}$ 
Compared with the 3 top-tier medical journals (New England Journal of Medicine, Lancet and Journal of American Medical Association), in which a significant increase ( $22 \%$ to $80 \%$ ) in the proportion of RCTs from 1974 to 2004 was found, ${ }^{39}$ the quality of orthodontic research still needs considerable improvement. However, the complexity of etiology, the variety of treatment modalities and prolonged treatment time in orthodontics can lead to difficulties in study design, ethics, practicality and maintaining quality. ${ }^{7,40}$ Furthermore, funding and recruitment can be challenging for trials in this field.$^{41}$ As a result, it can be difficult to carry out RCTs to answer certain orthodontic questions. Perhaps, this could be the reason that among the 64 SRs included, only 8 $(12.5 \%)$ were based exclusively on RCTs. Additionally, only four of the five included journals published level-1 studies during the past 3 years. The samples of our study only include clinical studies published in five leading specialist orthodontic journals. There are orthodontic SRs of RCTs published in medical journals and general dental journals but not captured by this study. ${ }^{42}$ Therefore, our findings could not represent the situation of all clinical studies in orthodontics.

It can be suggested that nonrandomized studies should only be conducted when RCTs are not feasible. ${ }^{43}$ In some cases, observational studies, though with higher risk of bias, might be the only source of data available for clinicians, and their importance to clinical practice is also associated with the magnitude of their effect sizes. ${ }^{44}$ Some quality evaluation systems have attempted to increase the weight of level-3 and level-4 studies that have met certain criteria. For instance, in GRADE, if observational studies have a large magnitude of effect, their quality of evidence will be rated up. ${ }^{14}$ The Oxford 2011 LOE also added similar criteria to its previous version, ${ }^{13}$ however, a specific definition of 'dramatic effect' was not provided. Considering these, we tried to combine Oxford LOE with the adjustment criteria of GRADE (Table 1). Three observational studies were therefore rated up during the assessment.

During the past 20 years, the proportion of orthodontic case reports has decreased from $31.4 \%$ to $17.58 \%,{ }^{32}$ indicating the awareness of clinicians and researchers on the quality of evidence hierarchy. In the present study, the number of level-4 studies varied among the 5 journals, while more than $70 \%$ were published in the $A J O-D O$. Gibson and Harrison presumed that this could be a result of $A J O-D O$ 's focus on publishing American Board of Orthodontists examinations' prize-winning cases. ${ }^{32}$ In addition, due to their important role in advancing knowledge on adverse effects and rare disorders, ${ }^{45}$ 
as well as the potential to facilitate precision and personalized orthodontics, ${ }^{46}$ case reports have particular merits among the designs of clinical studies in orthodontics.

In dentistry, to our knowledge, similar studies regarding LOE only exist in the fields of endodontics and oral \& maxillofacial surgery (OMFS). ${ }^{16,29,47,48}$ A comparison between these studies and the current one is presented in Table 4. However, readers should be cautious about these comparisons since different studies have used different eligibility criteria and different assessment tools for LOE.

In this study, we analyzed the association between LOE and the following factors: journals, funding status, geographical origin (first author), international collaboration, type of institution, multiple affiliations, and the international ranking of the first institution (according to 2018 QS top-50 dental schools), some of which had not been discussed in similar studies. ${ }^{16,29,47,48}$ The majority of included studies were conducted in universities $(86.7 \%)$, similar to the results of previous analyses of orthodontic research. ${ }^{49,50}$

Funding status was found to correlate with LOE, and studies funded by industry had significantly higher LOE. This is not surprising, as funding sources usually need to demonstrate that their funding is used for high quality research. This means, it is unlikely that a non-randomized clinical trial will be funded if there is scope for carrying out a randomized clinical trial in the same clinical area. However, our results are not in accordance with the findings of previous studies about LOE and financial support. ${ }^{28,51}$ This could be because some clinical areas may not be suitable to be tested using a randomized clinical trial methodology.

The geographic origin was also significantly associated with LOE. Studies from Europe performed significantly better in LOE and could account for larger proportion of clinical research than those from most of continents. This discrepancy might be explained by the differences among institutions and countries regarding the availability of research support. ${ }^{38}$ Because of the current emphasis on basic science research and stringent ethics policies, clinical trials may not be financially and ethically feasible, and the conduct of long-term cohort studies may not be valued.

\section{Strengths and limitations}

In this study, we have developed a novel LOE assessment tool combining the strengths of Oxford LOE and GRADE, which recognizes the possibility of observational studies 
to provide reliable evidence, and is applicable for the situation where clinicians need to quickly assess the evidence underlying a single study. In addition, we included a large sample of clinical studies in dentistry (Table 4). We also investigated 3 potential factors which have not been explored in previous similar studies.

Like any other literature assessment tools, LOE has its limitations. For example, although classified into different levels, studies with higher LOE do not always have higher clinical importance. ${ }^{51}$ First, the methodological and reporting quality can vary greatly among studies of the same design. Second, many important details of the study design, such as the selection of patient-centered research questions and outcome measures, are not considered by LOE. ${ }^{52-54}$ Hence, if time allows, we still advise readers to focus on not only study design but also specific methodological details, ${ }^{55-57}$ and to use multiple assessment tools when evaluating the quality of research articles.

\section{Conclusions}

- The number of high LOE studies in leading orthodontic journals was limited. There is still need for further improvement in the overall LOE of clinical studies in orthodontics.

- Financial support and geographic origin of the first author were significantly associated with LOE.

\section{Conflict of Interest}

None to declare. 


\section{References}

1. Watts G. Let's pension off the "major breakthrough". BMJ. 2007; 334 Suppl 1:s4.

2. Haynes RB, Devereaux PJ, Guyatt GH. Clinical expertise in the era of evidence-based medicine and patient choice. ACP Journal Club. 2002; 136:A11-14.

3. Faggion CM, Jr., Pachur T, Giannakopoulos NN. Patients' Values in Clinical DecisionMaking. J Evid Based Dent Pract. 2017; 17:177-183.

4. Rosenberg W, Donald A. Evidence based medicine: an approach to clinical problemsolving. BMJ. 1995; 310:1122-1126.

5. Luksanapruksa P, Millhouse PW. Level of Evidence Descriptions With Examples. Clin Spine Surg. 2016; 29:156-157.

6. Bastian H, Glasziou P, Chalmers I. Seventy-five trials and eleven systematic reviews a day: how will we ever keep up? PLoS Medicine. 2010; 7:e1000326.

7. Mulimani PS. Evidence-based practice and the evidence pyramid: A 21st century orthodontic odyssey. Am J Orthod Dentofacial Orthop. 2017; 152:1-8.

8. Ubbink DT, Guyatt GH, Vermeulen H. Framework of policy recommendations for implementation of evidence-based practice: a systematic scoping review. BMJ Open. 2013; 3:e001881.

9. Madhavji A, Araujo EA, Kim KB, Buschang PH. Attitudes, awareness, and barriers toward evidence-based practice in orthodontics. Am J Orthod Dentofacial Orthop. 2011; 140:309316.e302.

10. Obremskey WT, Pappas N, Attallah-Wasif E, Tornetta P, 3rd, Bhandari M. Level of evidence in orthopaedic journals. J Bone Joint Surg Am. 2005; 87:2632-2638.

11. Kay J, Memon M, Rogozinsky J, et al. Level of evidence of free papers presented at the European Society of Sports Traumatology, Knee Surgery and Arthroscopy congress from 2008 to 2016. Knee Surg Sports Traumatol Arthrosc. 2017; 25:602-607.

12. Sugrue CM, Joyce CW, Sugrue RM, Carroll SM. Trends in the Level of Evidence in Clinical Hand Surgery Research. Hand (New York). 2016; 11:211-215.

13. Jeremy Howick, Iain Chalmers (James Lind Library), Paul Glasziou TG, et al. The Oxford 2011 Levels of Evidence. Oxford Centre for Evidenced-Based Medicine. http://www.cebm.net/index.aspx?o=5653. Accessed 21 October, 2017.

14. Guyatt GH, Oxman AD, Sultan S, et al. GRADE guidelines: 9. Rating up the quality of evidence. J Clin Epidemiol. 2011; 64:1311-1316. 
15. Peck S. "Philosophy" and evidence-based orthodontics. Angle Orthod. 1997; 67:403.

16. Shafiei L, Shahravan A. The level of evidence in two leading endodontic journals. Iran Endod J. 2013; 8:18-21.

17. Joyce KM, Joyce CW, Kelly JC, Kelly JL, Carroll SM. Levels of Evidence in the Plastic Surgery Literature: A Citation Analysis of the Top 50 'Classic' Papers. Arch Plast S. 2015; 42:411-418.

18. Jacobson DA, Bhanot K, Yarascavitch B, Chuback J, Rosenbloom E, Bhandari M. Levels of evidence: a comparison between top medical journals and general pediatric journals. BMC Pediatrics. 2015; 15:3.

19. Moraes FY, Bonifacio LA, Marta GN, et al. Hierarchy of evidence referring to the central nervous system in a high-impact radiation oncology journal: a 10-year assessment. Descriptive critical appraisal study. Sao Paulo medical journal = Revista paulista de medicina. 2015; 133:307-313.

20. Reuters T. 2016 Journal Citation Reports ${ }^{\circledR}$ Science Edition. 2017; https://jcr.incites.thomsonreuters.com/JCR JournalHomeAction.action. Accessed 11 Nov, 2017.

21. Livas C, Pandis N, Ren Y. Full-text publication of abstracts presented at European Orthodontic Society congresses. Eur J Orthod. 2014; 36:569-575.

22. Page MJ, Shamseer L, Altman DG, et al. Epidemiology and Reporting Characteristics of Systematic Reviews of Biomedical Research: A Cross-Sectional Study. PLoS Medicine. 2016; 13:e1002028.

23. Oxford Centre for Evidence-based Medicine. Levels of Evidence. March 2009; http://www.cebm.net/oxford-centre-evidence-based-medicine-levels-evidence-march2009/. Accessed 21 October, 2017.

24. Greenhalgh T. How to read a paper. Getting your bearings (deciding what the paper is about). BMJ. 1997; 315:243-246.

25. Koletsi D, Pandis N, Polychronopoulou A, Eliades T. What's in a title? An assessment of whether randomized controlled trial in a title means that it is one. Am J Orthod Dentofacial Orthop. 2012; 141:679-685.

26. Balshem H, Helfand M, Schunemann HJ, et al. GRADE guidelines: 3 . Rating the quality of evidence. J Clin Epidemiol. 2011; 64:401-406.

27. Landis JR, Koch GG. The measurement of observer agreement for categorical data. 
Biometrics. 1977; 33:159-174.

28. Foughty Z, Antalis MS, Ringenberg J, Hall AD. Funding sources and financial disclosures, and their relationship to study outcomes and level of evidence in the Journal of Shoulder and Elbow Surgery. J Shoulder Elb Surg. 2017; 26:e193-e197.

29. Sandhu A. The evidence base for oral and maxillofacial surgery: 10-year analysis of two journals. Br J Oral Maxillofac Surg. 2012; 50:45-48.

30. QS. The QS World University Rankings of Dentistry. 2018; https:/www.topuniversities.com/university-rankings/university-subject-

rankings/2018/dentistry. Accessed 3 July, 2018.

31. Brignardello-Petersen R, Carrasco-Labra A, Glick M, Guyatt GH, Azarpazhooh A. A practical approach to evidence-based dentistry: III: how to appraise and use an article about therapy. JADA. 2015; 146:42-49.e41.

32. Gibson R, Harrison J. What are we reading? An analysis of the orthodontic literature 1999 to 2008. Am J Orthod Dentofacial Orthop. 2011; 139:e471-484.

33. Fletcher RH, Fletcher SW. Clinical research in general medical journals: a 30-year perspective. N Engl J Med. 1979; 301:180-183.

34. Brophy RH, Gardner MJ, Saleem O, Marx RG. An assessment of the methodological quality of research published in The American Journal of Sports Medicine. Am J Sport Med. 2005; 33:1812-1815.

35. Del Fabbro M, Corbella S, Tsesis I, Taschieri S. The trend of quality of publications in endodontic surgery: a 10-year systematic survey of the literature. J Evid Based Dent Pract. $2015 ; 15: 2-7$.

36. Baker B. Evidence-based therapy: an orthodontic dilemma. Am J Orthod Dentofacial Orthop. 2006; 130:272; author reply 272.

37. Kokich VG. Do you have an evidence-based practice? Am J Orthod Dentofacial Orthop. $2013 ; 143: 1$.

38. Kanavakis G, Dombroski MM, Malouf DP, Athanasiou AE. Demographic characteristics of systematic reviews, meta-analyses, and randomized controlled trials in orthodontic journals with impact factor. Eur J Orthod. 2016; 38:57-65.

39. Teoh DC, Schramm B. Changes in clinical research in anaesthesia and intensive care from 1974-2004. Anaesth Intens Care. 2006; 34:753-757.

40. Shimada T, Takayama H, Nakamura Y. Quantity and quality assessment of randomized 
controlled trials on orthodontic practice in PubMed. Angle Orthod. 2010; 80:525-530.

41. Cunningham S, Bearn D, Benson P, et al. In search of the sample: recent experiences of a trial team in orthodontics. Contemp Clin Trials. 2011; 32:530-534.

42. Alqaydi AR, Kanavakis G, Naser-Ud-Din S, Athanasiou AE. Authorship characteristics of orthodontic randomized controlled trials, systematic reviews, and meta-analyses in nonorthodontic journals with impact factor. Eur J Orthod. 2017.

43. Deeks JJ, Dinnes J, D'Amico R, et al. Evaluating non-randomised intervention studies. Health Technol Asses. 2003; 7:iii-x, 1-173.

44. Piccirillo JF. Improving the Quality of the Reporting of Research Results. JAMA Otolaryngol Head Neck Surg. 2016; 142:937-939.

45. Nissen T, Wynn R. The clinical case report: a review of its merits and limitations. BMC Res Notes. 2014; 7:264.

46. Jheon AH, Oberoi S, Solem RC, Kapila S. Moving towards precision orthodontics: An evolving paradigm shift in the planning and delivery of customized orthodontic therapy. Orthod Craniofac Res. 2017; 20 Suppl 1:106-113.

47. Kontakiotis EG, Filippatos CG, Agrafioti A. Levels of evidence for the outcome of regenerative endodontic therapy. J Endod. 2014; 40:1045-1053.

48. Lau SL, Samman N. Levels of evidence and journal impact factor in oral and maxillofacial surgery. Int J Oral Maxillofac Surg. 2007; 36:1-5.

49. Tsichlaki A, Chin SY, Pandis N, Fleming PS. How long does treatment with fixed orthodontic appliances last? A systematic review. Am J Orthod Dentofacial Orthop. 2016; 149:308-318.

50. Al-Moghrabi D, Tsichlaki A, Pandis N, Fleming PS. Collaboration in orthodontic clinical trials: prevalence and association with sample size and funding. Prog Orthod. 2018; 19:16.

51. Gouveia CJ, Zaghi S, Awad M, et al. Publication trends and levels of evidence in obstructive sleep apnea literature. Laryngoscope. 2018.

52. John MT. Health Outcomes Reported by Dental Patients. J Evid Based Dent Pract. 2018; 18:332-335.

53. Hua F. Increasing the value of orthodontic research through the use of dental patientreported outcomes. J Evid Based Dent Pract. 2019; In press.

54. Reissmann DR. Dental patient-reported outcome measures are essential for evidence-based prosthetic dentistry. J Evid Based Dent Pract. 2019; 
https://doi.org/10.1016/j.jebdp.2019.01.003; In press.

55. Koletsi D, Spineli LM, Lempesi E, Pandis N. Risk of bias and magnitude of effect in orthodontic randomized controlled trials: a meta-epidemiological review. Eur J Orthod. 2016; 38:308-312.

56. Faggion CM, Jr. Evaluating the Risk of Bias of a Study. J Evid Based Dent Pract. 2015; 15:164-170.

57. Isaacson RJ. Evidence-based orthodontics. Angle Orthod. 2002; 72:iv. 


\section{Tables}

Table 1. The modified LOE assessment tool used in this study.

\begin{tabular}{l|l|l}
\hline LOE & Description & Summary \\
\cline { 1 - 2 } Level 1 & Systematic reviews of randomized trials or n-of-1 trials & \\
\hline Level 2 & $\begin{array}{l}\text { Randomized controlled trials } \\
\text { Observational studies with dramatic effect a } \\
\text { Systematic reviews of cohort studies with or without } \\
\text { randomized trials }\end{array}$ & High \\
\hline Level 3 & $\begin{array}{l}\text { Non-randomized and/or uncontrolled trials } \\
\text { Cohort studies. } \\
\text { Systematic reviews of case-control studies with or } \\
\text { without cohort studies }\end{array}$ & \\
\hline & $\begin{array}{l}\text { Case-control studies } \\
\text { Case-series and Case reports } \\
\text { Historically controlled studies } \\
\text { Cross-sectional studies }\end{array}$ & \multirow{2}{*}{ Low } \\
\hline
\end{tabular}

a When the primary outcome of a study was categorical and the risk ratio (RR) was greater than 5 (or less than 0.2), we considered the effect dramatic. If the sample size and odds ratio (OR) were provided, we calculated the corresponding RR, then decided whether or not to rate up (6). 
Table 2. Characteristics of included articles from 5 leading orthodontic journals during the 3-year period

\begin{tabular}{|c|c|c|c|c|c|c|c|}
\hline \multirow[t]{2}{*}{ Characteristic } & \multirow[t]{2}{*}{ Category } & \multicolumn{6}{|c|}{ n (\%) } \\
\hline & & EJO & AJO-DO & AO & KJO & OCR & Total \\
\hline \multirow[t]{3}{*}{ Publication year } & 2015 & $33(34.7 \%)$ & $71(27.6 \%)$ & $72(36.5 \%)$ & $19(36.5 \%)$ & $15(41.7 \%)$ & 210 (33.0\%) \\
\hline & 2016 & $29(30.6 \%)$ & 98 (38.2\%) & $70(35.5 \%)$ & $13(25.0 \%)$ & $6(16.7 \%)$ & $216(33.9 \%)$ \\
\hline & 2017 & $33(34.7 \%)$ & $88(34.2 \%)$ & $55(28.0 \%)$ & $20(38.5 \%)$ & $15(41.7 \%)$ & $211(33.1 \%)$ \\
\hline \multirow[t]{3}{*}{ Financial support } & Unfunded/unreported & $62(65.3 \%)$ & $192(74.7 \%)$ & $134(68.0 \%)$ & $29(55.8 \%)$ & $15(41.7 \%)$ & $432(67.8 \%)$ \\
\hline & Funded by other sources & $29(30.5 \%)$ & $58(22.6 \%)$ & $56(28.4 \%)$ & $23(44.2 \%)$ & $20(55.6 \%)$ & $186(29.2 \%)$ \\
\hline & Funded by industry & $4(4.2 \%)$ & $7(2.7 \%)$ & $7(3.6 \%)$ & $0(0.0 \%)$ & $1(2.7 \%)$ & $19(3.0 \%)$ \\
\hline International collaboration & & $34(35.8 \%)$ & $66(25.7 \%)$ & $55(27.9 \%)$ & $9(17.3 \%)$ & $14(38.9 \%)$ & $178(27.9 \%)$ \\
\hline QS top-50 dental school & & 27 (28.4\%) & $59(23.0 \%)$ & $31(15.7 \%)$ & $13(25.0 \%)$ & $3(8.3 \%)$ & $133(20.9 \%)$ \\
\hline Multiple affiliations & & $70(73.7 \%)$ & $170(66.1 \%)$ & $132(67.0 \%)$ & $31(59.6 \%)$ & 27 (75.0\%) & $430(67.5 \%)$ \\
\hline \multirow[t]{6}{*}{ Geographic origin } & Europe & $68(71.6 \%)$ & 77 (30.0\%) & $84(42.6 \%)$ & $13(25.0 \%)$ & 20 (55.6\%) & $262(41.1 \%)$ \\
\hline & Asia & $14(14.7 \%)$ & 84 (32.7\%) & $52(26.4 \%)$ & 36 (69.2\%) & $6(16.7 \%)$ & $192(30.1 \%)$ \\
\hline & North America & $5(5.3 \%)$ & $42(16.3 \%)$ & 37 (18.8\%) & $2(3.8 \%)$ & $8(22.2 \%)$ & 94 (14.8\%) \\
\hline & South America & $5(5.3 \%)$ & 41 (16.0\%) & $21(10.7 \%)$ & $1(1.9 \%)$ & $2(5.6 \%)$ & $70(11.0 \%)$ \\
\hline & Africa & $1(1.1 \%)$ & $9(3.5 \%)$ & $3(1.5 \%)$ & $0(0.0 \%)$ & $0(0.0 \%)$ & $13(2.1 \%)$ \\
\hline & Oceania & $2(2.1 \%)$ & $4(1.6 \%)$ & $0(0.0 \%)$ & $0(0.0 \%)$ & $0(0.0 \%)$ & $6(0.9 \%)$ \\
\hline
\end{tabular}


Table 2. Characteristics of included articles from 5 leading orthodontic journals during the 3-year period (Continued)

\begin{tabular}{|c|c|c|c|c|c|c|c|}
\hline \multirow[t]{2}{*}{ Characteristic } & \multirow[t]{2}{*}{ Category } & \multicolumn{6}{|c|}{ n (\%) } \\
\hline & & EJO & AJO-DO & AO & KJO & OCR & Total \\
\hline \multirow[t]{4}{*}{ Type of institution } & University & 87 (91.6\%) & $215(83,7 \%)$ & $171(86.8 \%)$ & 48 (92.3\%) & 31 (86.1\%) & 552 (86.7\%) \\
\hline & Public health service & $1(1.1 \%)$ & $1(0.4 \%)$ & $1(0.5 \%)$ & $0(0.0 \%)$ & $0(0.0 \%)$ & $3(0.5 \%)$ \\
\hline & Private practice & $3(3.2 \%)$ & $31(12.1 \%)$ & $21(10.7 \%)$ & $4(7.7 \%)$ & $2(5.6 \%)$ & $61(9.6 \%)$ \\
\hline & Others & $4(4.2 \%)$ & $10(3.9 \%)$ & $4(2.0 \%)$ & $0(0.0 \%)$ & $3(8.3 \%)$ & $21(3.3 \%)$ \\
\hline \multirow[t]{7}{*}{ Study design } & SRs & $25(26.3 \%)$ & $17(6.6 \%)$ & $15(7.6 \%)$ & $3(5.8 \%)$ & $4(11.1 \%)$ & $64(10.0 \%)$ \\
\hline & RCTs & 24 (25.3\%) & $39(15.2 \%)$ & $44(22.3 \%)$ & $4(7.7 \%)$ & $4(11.1 \%)$ & $115(18.1 \%)$ \\
\hline & Cohort studies & $43(45.3 \%)$ & 109 (42.4\%) & $120(60.9 \%)$ & $29(55.7 \%)$ & $18(50.0 \%)$ & 319 (50.1\%) \\
\hline & $\begin{array}{l}\text { Cross-sectional } \\
\text { studies }\end{array}$ & $3(3.1 \%)$ & $5(1.9 \%)$ & $4(2.0 \%)$ & $0(0.0 \%)$ & $9(25.0 \%)$ & $21(3.3 \%)$ \\
\hline & Case-control studies & $0(0.0 \%)$ & $2(0.8 \%)$ & $1(0.6 \%)$ & $0(0.0 \%)$ & $1(2.8 \%)$ & $4(0.6 \%)$ \\
\hline & Case-series and & $0(0.0 \%)$ & $85(33.1 \%)$ & $13(6.6 \%)$ & $16(30.8 \%)$ & $0(0.0 \%)$ & 114 (17.9\%) \\
\hline & Case reports & & & & & & \\
\hline Total & & 95 (14.9\%) & 257 (40.3\%) & 197 (30.9\%) & $52(8.2 \%)$ & $36(5.7 \%)$ & $637(100 \%)$ \\
\hline
\end{tabular}


Table 3. Univariable and multivariable logistic regression derived odd ratios (OR) and $95 \%$ confidence intervals (CI), with LOE ( $1 \leqslant L O E \leqslant 2$ vs. $3 \leqslant$ $\mathrm{LOE} \leqslant 4$ ) as the dependent variable.

\begin{tabular}{|c|c|c|c|c|c|c|c|}
\hline \multirow[t]{2}{*}{ Independent variable } & \multirow[t]{2}{*}{ Category } & \multicolumn{3}{|c|}{ Univariable } & \multicolumn{3}{|c|}{ Multivariable $^{a}$} \\
\hline & & OR & $95 \% \mathrm{Cl}$ & $P$ value & OR & $95 \% \mathrm{Cl}$ & $P$ value \\
\hline \multirow[t]{2}{*}{ International collaboration } & No & Reference & & 0.681 & & & \\
\hline & Yes & 1.085 & $(0.74,1.60)$ & & & & \\
\hline \multirow[t]{2}{*}{ QS Top-50 dental school } & No & Reference & & 0.180 & & & \\
\hline & Yes & 0.732 & $(0.46,1.16)$ & & & & \\
\hline \multirow[t]{2}{*}{ Multiple affiliations } & No & Reference & & 0.206 & & & \\
\hline & Yes & 1.282 & $(0.87,1.89)$ & & & & \\
\hline \multirow[t]{3}{*}{ Funding status } & Funded by industry & Reference & & 0.005 & Reference & & 0.003 \\
\hline & $\begin{array}{l}\text { Funded by other } \\
\text { sources }\end{array}$ & 0.298 & $(0.11,0.78)$ & & 0.352 & $(0.13,0.99)$ & \\
\hline & Unfunded/unreported & 0.228 & $(0.09,0.58)$ & & 0.223 & $(0.08,0.60)$ & \\
\hline \multirow[t]{4}{*}{ Type of institution } & University & Reference & & 0.703 & & & \\
\hline & Public health service & 1.378 & $(0.12,15.31)$ & & & & \\
\hline & Private Practice & 0.746 & $(0.39,1.42)$ & & & & \\
\hline & Others & 1.378 & $(0.55,3.48)$ & & & & \\
\hline \multirow[t]{5}{*}{ Journal of publication } & EJO & Reference & & $<0.001$ & Reference & & $<0.001$ \\
\hline & AJO-DO & 0.277 & $(0.17,0.46)$ & & 0.322 & $(0.19,0.55)$ & \\
\hline & $\mathrm{AO}$ & 0.423 & $(0.26,0.70)$ & & 0.482 & $(0.28,0.82)$ & \\
\hline & $\mathrm{KJO}$ & 0.139 & $(0.05,0.36)$ & & 0.178 & $(0.07,0.47)$ & \\
\hline & OCR & 0.257 & $(0.10,0.64)$ & & 0.249 & $(0.10,0.64)$ & \\
\hline
\end{tabular}


Table 3. Univariable and multivariable logistic regression derived odd ratios (OR) and $95 \%$ confidence intervals (CI), with LOE ( $1 \leqslant L O E \leqslant 2$ vs. $3 \leqslant$ $\mathrm{LOE} \leqslant 4$ ) as the dependent variable. (Continued)

\begin{tabular}{|c|c|c|c|c|c|c|c|}
\hline \multirow[t]{2}{*}{ Independent variable } & \multirow[t]{2}{*}{ Category } & \multicolumn{3}{|c|}{ Univariable } & \multicolumn{3}{|c|}{ Multivariable $^{a}$} \\
\hline & & OR & $95 \% \mathrm{Cl}$ & $P$ value & OR & $95 \% \mathrm{Cl}$ & $P$ value \\
\hline \multirow[t]{6}{*}{ Geographic origin } & Europe & Reference & & $<0.001$ & Reference & & 0.006 \\
\hline & Asia & 0.472 & $(0.30,0.73)$ & & 0.591 & $(0.36,0.96)$ & \\
\hline & North America & 0.468 & $(0.26,0.83)$ & & 0.540 & $(0.30,0.99)$ & \\
\hline & South America & 0.539 & $(0.29,1.01)$ & & 0.684 & $(0.36,1.32)$ & \\
\hline & Africa & 3.164 & $(1.01,9.96)$ & & 4.850 & $\begin{array}{l}(1.49 \\
15.80)\end{array}$ & \\
\hline & Oceania & 0.989 & $(0.18,5.50)$ & & 0.791 & $(0.13,4.89)$ & \\
\hline
\end{tabular}

${ }^{a}$ Model summary: dependent variable coding: [0] $3 \leqslant \mathrm{LOE} \leqslant 4$, [1] $1 \leqslant \mathrm{LOE} \leqslant 2$; No. (less common event) = 169; P (Hosmer \& Lemeshow) = 0.228;

$\mathrm{R}^{2}($ Nagelkerke) $=0.132$ 
Table 4. Comparison of assessment results between this study and previous similar research regarding LOE in other fields of dentistry

\begin{tabular}{lccccc}
\hline Study ID & Current study & $\begin{array}{c}\text { Lau (2007) } \\
\mathbf{( 4 8 )}\end{array}$ & $\begin{array}{c}\text { Sandhu (2010) } \\
\mathbf{( 2 9 )}\end{array}$ & Shafiei (2013) (16) & Kontakiois (2014) (47) \\
\hline Area & Orthodontics & OMFS & OMFS & Endodontics & Endodontics \\
Sample size (included) & $2100(637)$ & $932(467)$ & $3294(1986)$ & $1357(222)$ & $326(51)$ \\
Period & $2015-2017$ & $2002-2003$ & $1999-2009$ & 2000,2006 and 2010 & $1993-2013$ \\
LOE Classification Tool & Oxford LOE 2011 & NHMRC b & AHCPR & RDC d & Oxford LOE 2009 \\
Proportion of Level 1 studies & $1.26 \%$ & $0 \%$ & $3.47 \%$ & $26.13 \%$ & $0 \%$ \\
Proportion of Level 2 studies & $25.12 \%$ & $4 \%$ & $28.90 \%$ & $5.41 \%$ & $39.21 \%$ \\
Proportion of Level 3 studies & $51.18 \%$ & $16 \%$ & $3.27 \%$ & $44.59 \%$ & $0 \%$ \\
Proportion of Level 4 studies & $22.45 \%$ & $80 \%$ & $64.36 \%$ & $2.70 \%$ & $15.69 \%$ \\
Proportion of Level 5 studies & - & - & - & $21.17 \%$ & $80.39 \%$ \\
\hline
\end{tabular}

a OMFS = Oral and maxillofacial surgery

b $N H M R C=$ Australian National Health and Medical Research Council guidelines

c $A H C P R=$ US Agency for Health Care Policy and Research

d $R D C=$ The National Health Service Research and Development Centre for Evidence-based Medicine 


\section{Figure Legends}

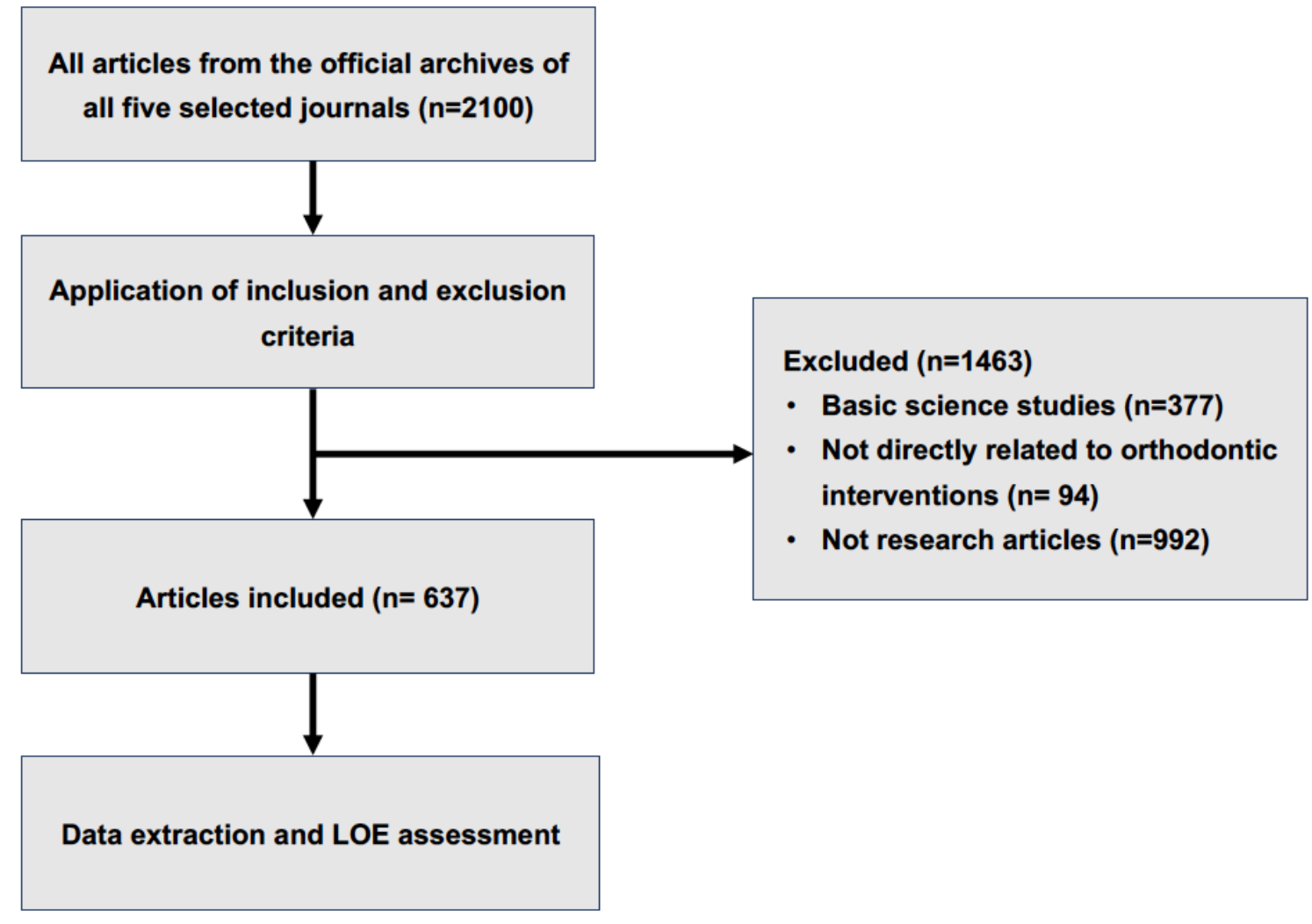

Figure 1. Flow diagram of the included articles. 

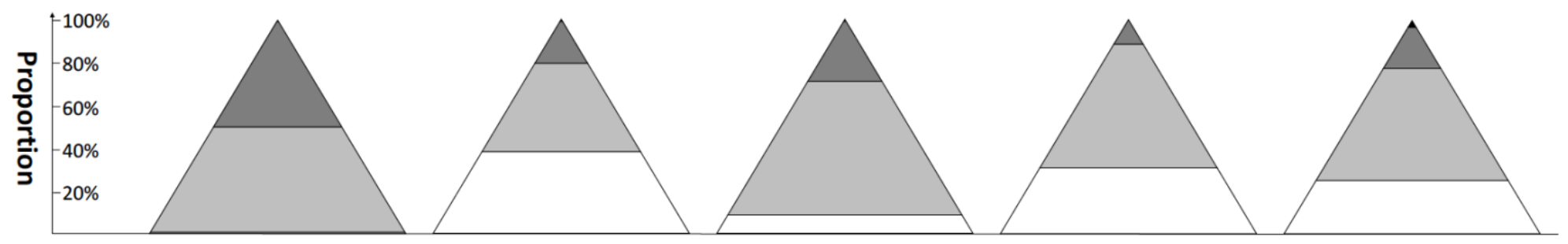

Level-1

Level-2

Level-3

Level-4

\begin{tabular}{r|c|c|c|c|c|}
\multicolumn{2}{c}{ EJO } & AJO-DO & AO & KJO & OCR \\
\hline Level-1 & $2(2.1 \%)$ & $3(1.2 \%)$ & $2(1.0 \%)$ & $0(0.0 \%)$ & $1(2.8 \%)$ \\
\hline Level-2 & $44(46.3 \%)$ & $50(19.5 \%)$ & $54(27.4 \%)$ & $6(11.5 \%)$ & $6(16.7 \%)$ \\
\hline Level-3 & $46(48.4 \%)$ & $107(41.6 \%)$ & $123(62.5 \%)$ & $30(57.7 \%)$ & $20(55.5 \%)$ \\
\hline Level-4 & $3(3.2 \%)$ & $97(37.7 \%)$ & $18(9.1 \%)$ & $16(30.8 \%)$ & $9(25.0 \%)$ \\
\hline Total & $95(100.0 \%)$ & $257(100.0 \%)$ & $197(100.0 \%)$ & $52(100.0 \%)$ & $36(100.0 \%)$ \\
\hline
\end{tabular}

Figure 2. A pyramid plot showing the proportion of studies of different LOE by journals. 